Department of Economics - FEA/USP

\title{
A Green Lewis Development Model
}

GUILHERME DE OLIVEIRA

GILBERTO TADEU LIMA

WORKING PAPER SERIES № 2015-49 


\title{
DEPARTMENT OF ECONOMICS, FEA-USP \\ WORKING PAPER № 2015-49
}

\section{A Green Lewis Development Model}

\author{
Guilherme de Oliveira (guilherme.decon@usp.br) \\ Gilberto Tadeu Lima (giltadeu@usp.br)
}

\begin{abstract}
:
This paper develops an environmental extension of a Lewis dual economy model, in which the interaction between environmental quality and economic growth, in one of its several dimensions, is explicitly modeled to explore long-run effects of a pollution abatement rule in developing economies. The government requires the Modern sector to dedicate a fraction of its output to pollution abatement, with such profitability-reducing fraction being endogenous to the level of environmental quality. Meanwhile, the level of environmental quality positively affects labor productivity, profits and, therefore, savings, which has a positive impact on capital accumulation. It is shown that this pollution abatement requirement, by affecting profitability in the Modern sector both negatively and positively, makes for the emergence of an ecological development trap from which a developing dual economy, if left to the free play of its structural forces, never escapes. Fortunately, however, this economy can be released from such a trap not only through a standard Big Push, in the spirit of Rosenstein-Rodan, but also by means of what we call an Environmental Big Push.
\end{abstract}

Keywords: Ecological development trap; Environmental Big Push; Economic development; Environmental quality.

JEL Codes: 011; 044; Q50. 


\title{
A Green Lewis Development Model*
}

\author{
Guilherme de Oliveira \\ Department of Economics, University of São Paulo, Brazil. \\ guilherme.decon@usp.br \\ $\&$ \\ Gilberto Tadeu Lima \\ Department of Economics, University of São Paulo, Brazil. \\ giltadeu@usp.br
}

\begin{abstract}
This paper develops an environmental extension of a Lewis dual economy model, in which the interaction between environmental quality and economic growth, in one of its several dimensions, is explicitly modeled to explore long-run effects of a pollution abatement rule in developing economies. The government requires the Modern sector to dedicate a fraction of its output to pollution abatement, with such profitability-reducing fraction being endogenous to the level of environmental quality. Meanwhile, the level of environmental quality positively affects labor productivity, profits and, therefore, savings, which has a positive impact on capital accumulation. It is shown that this pollution abatement requirement, by affecting profitability in the Modern sector both negatively and positively, makes for the emergence of an ecological development trap from which a developing dual economy, if left to the free play of its structural forces, never escapes. Fortunately, however, this economy can be released from such a trap not only through a standard Big Push, in the spirit of Rosenstein-Rodan, but also by means of what we call an Environmental Big Push.
\end{abstract}

Keywords: Ecological development trap; Environmental Big Push; Economic development; Environmental quality.

JEL: O11, O44, Q50.

*Peter Skott, Arslan Razmi, Julia M. da Costa, Raphael R. Gouvea, and Richard Simpson provided valuable comments and suggestions on earlier versions of this paper. We would also like to thank Klara Zwickl for drawing key parts of the literature to our attention. The usual disclaimer applies. Guilherme de Oliveira worked on this paper while visiting the Department of Economics of University of Massachusetts - Amherst, whose hospitality and support are gratefully acknowledged. 


\section{Introduction}

In recent years there has emerged considerable, if not conclusive, scientific evidence that anthropogenic greenhouse gas (GHG) emissions accelerate the natural process of climate change on Earth (IPCC, 2014). Environmental economics has incorporated such evidence, and its consequences, in macroeconomic models of optimal exploitation of natural resources, e.g. Solow (1974). However, the literature has not paid sufficient attention to the limited ability of the Planet to act as a sink for capitalist waste, and the challenge that it poses to economic growth and development theory.

A notable exception and important contribution is "The Green Solow Model" set forth in Brock and Taylor (2010). ${ }^{1}$ This work is an elegant combination of Solow's (1956) model and the Environmental Kuznets Curve (EKC). The authors start with a technology that combines capital and labor to produce a single good through constant returns to scale, which in turn generates emissions that must be mitigated through an abatement mechanism. As the production function is concave, given the assumption of diminishing marginal returns to capital, externalities also exhibit a non-linear pattern in the inverted U-shaped format - the EKC. This formalization contributes to improve the estimation quality of convergence in per capita $\mathrm{CO}_{2}$ emissions, one of the main motivations of the paper.

The Green Solow model has an optimistic message to developing countries. It suggests that it may be enough to allocate a fraction of economic activity to abatement while, at same time, the economy accumulates capital to improve the level of environmental quality and per capita income. There is no any endogenous force in such environmental policy that can qualitatively compromise the transition of a particular country to the steady state. ${ }^{2}$

This message confronts a political argument of many developing countries that see restrictive instruments for environmental control, such as emission targets, as an obstacle to economic development, which can prevent them from achieving the economic level of developed, rich countries (Green et al., 2014). Based on these interregional justice arguments, the political view that is gaining prominence is that without international environmental compensations policies, developing economies will be unable to have higher growth rates while at the same time reducing their emissions. ${ }^{3}$ By contrast, the Green Solow model seems to imply that designing compensation policies for developing countries is not necessary.

Recent econometric evidence suggests that pollution costs are already high in many economies, as it has been found, for instance, that exposure to a poor environment can decrease labor productivity (Graff Zivin and Neidell, 2012), and has long-term consequences on health and human capital (Currie et al., 2009). Thus, for some developing countries, a direct implementation of the abatement mechanism embodied in the Green Solow model would imply in a steady decrease of

\footnotetext{
${ }^{1}$ See Copeland and Taylor (1994), and Stokey (1998) for other examples.

${ }^{2}$ Brock and Taylor (2010, p. 136) are careful enough to mention that such conclusions are valid in a context in which the intensity of abatement is fixed, and "there are no political economy or intergenerational conflict to resolve".

${ }^{3}$ See Nagashima et al. (2009) and Verbruggen (2009) for some discussions on and simulations of international environment agreements.
} 
environmental quality over the subsequent decades, which might compromise capital accumulation and economic development. Along with pollution costs imposed by abatement targets, such mechanism may result in a fall of savings, which in turn, may create economic conditions for the formation of a new source of development trap in developing economies.

This particular feature is not captured by models a la Solow (1956), since such models, given several of their assumptions, is best seen as describing the pattern of economic growth in mature economies, unlike the models in the tradition of the pioneers of economic development, such as Nurkse (1952), Rosenstein-Rodan (1943), and, especially, Lewis (1954). In their view, in developing economies, among other structural features, the labor force is usually not a binding constraint, capital accumulation is not necessarily subject to diminishing returns, and natural resources play an important role. These structural characteristics are still found, mutatis mutandi, in many developing countries, and can crucially affect the pattern of convergence to the steady state with achievement of maturity through the emergence of development traps.

Thus, the economic implications that arise from the standard prediction of the Green Solow model pose a natural question: are not developing countries structurally any different? In other words, is the dynamic of long-run convergence to the steady state with achievement of maturity any different for a developing economy, in the sense that a simple environmental policy can prevent them from achieving the mature phase? In this context, the main goal and contribution of this paper is to develop a "green" extension of a Lewis dual economy model, in which the macroeconomy and the environment interact, thus illustrating some of the structural characteristics and mechanisms mentioned above.

These issues are explored using a similar framework to the Green Solow model, but in a developing macroeconomics context, inspired in Ros (2013). It is shown that abatement policies without international compensation mechanisms may result in an ecological development trap, from which a developing economy, if left to the free play of its structural forces, may never escape, a prediction in the spirit of the pioneers of development economics. Despite this potentially pessimistic message, it is also shown that in some particular cases, exogenous compensation strategies can help developing countries to get (back) on track to maturity, even if a long track, through either a standard Big Push, or what we call an environmental Big Push.

The remainder of the paper is organized as follows: Section 2 describes the general framework, and Section 3 presents the building blocks of the model. Section 3.1 analyzes the behavior of the model in the long run. The balanced growth and (in)stability conditions are qualitatively analyzed in subsection 3.1.1, in which a possible configuration of multiple equilibria and development trap is explored. The paper closes with a summary of the main conclusions derived along the way, and some final comments.

\section{General framework}

The model presented in the subsequent section is a Lewis dual economy model in which the environment plays an important role. To understand the general framework, consider an economy 
that is closed and has no explicit fiscal activities. In addition, suppose that this economy follows a pollution abatement rule, which is defined by the government according to some level of negative externalities on the environment that must be mitigated.

The dualism is represented by two sectors that produce a single good used for both consumption and investment: the Traditional $T$ and the Modern $M$. Moreover, there are two possible phases of development: the surplus labor (or underdevelopment) phase and the mature (or developed) phase. The underdevelopment is characterized by the coexistence of the two sectors and, therefore, as the $T$ sector is a reserve of abundant labor, also by an unlimited supply of labor to the $M$ sector. Meanwhile, the developed phase, or maturity, begins when the $T$ sector ceases to exist and, therefore, the supply of labor to the $M$ sector becomes inelastic as in the Solow (1956) model.

The $M$ sector combines physical capital with labor in a Cobb-Douglas production function with constant returns to scale, jointly producing the M-good and a flow of pollution. A governmental authority requires the $M$ sector to dedicate a fraction of its production to abatement. This fraction is calibrated according to a rule that is endogenous to the level of environmental quality.

When the economy is in the underdevelopment phase, it is supposed that the amount of negative externalities comes from the production process of a local urban $M$ sector. In addition, such economy is exogenously affected by the level of negative externalities generated by developed countries, through a mechanism of pollution transfer. In such case, the sensitivity of a developing country to this international problem is inversely related to its level of economic development: the less developed is the economy, the greater is its sensitivity to this pollution transfer. Once maturity is achieved, it is supposed that this negative effect ceases. For simplicity, this pollution transfer is treated as exogenous, and free of any monetary compensation mechanism. ${ }^{4}$

Some real-world features on the interaction between the environment and development seems to justify such simple theoretical assumption. Jacob and Marschinski (2013), for example, argue that most industrialized countries are net importers of carbon emissions, that is, they release fewer emissions for the production of their total exported goods and services than the amount generated by their developing countries trading partners for producing their total imported goods and services. In this sense, the negative environmental impact embodied in trade can be seen as a mechanism of pollution transfer. Another well-documented pollution transfer mechanism is the international trade in waste products, which has been negatively affecting especially developing countries in Africa. Exploring such an evidence, Copeland (1991), for instance, developed a model to analyze the welfare effects of international trade in waste products in the presence of illegal disposal. The author argues that taxation to control externalities associated with waste disposal in this economies can be welfare improving.

To complement this dualism, it is supposed that the $T$ sector houses a surplus labor that is large enough to ensure an infinitely elastic supply of labor in both sectors at the subsistence wage,

\footnotetext{
${ }^{4}$ An important aspect of environmental externalities takes place in a global scale, in which the weak capacity of developing countries to adapt to climate change may play an important role. However, as this model is a one-country model, we abstract from more complex pollution interactions between countries. See Razmi (2015) for a model that explores similar environmental dynamics in a North-South economic context.
} 
which in turn, is equal to the average product of effective labor in the $T$ sector (Lewis, 1954). For simplicity, it is supposed that the pollution in the $T$ sector is negligible. Wages in the $M$ sector are determined by the wages in the $T$ sector, plus a wage premium that must be paid to attract workers from the Traditional sector. This wage premium compensates for any economic and psychological costs of migrating. The Lewisian dualism persists until the $T$ sector disappears when all workers are attracted to the $M$ sector, and the supply of labor becomes inelastic to wages.

The environmental dimension is represented by an index of environmental quality, $\epsilon$. Therefore, the pollution generated by the $M$ sector reduces the level of environmental quality in the economy. It is supposed that if this negative impact is persistent, the exposure to a poor environment can lower labor productivity, through health and cognitive channels. To model this effect, we specify a process of labor-augmenting technical change that is endogenous to the level of environmental quality. ${ }^{5}$

This latter assumption is based on recent robust empirical evidence, such as that provided by Graff Zivin and Neidell (2012), who found a causal relation between the variations in the atmosphere ozone concentration and the labor productivity of American farmers. They find that a $10 \mathrm{ppb}$ (parts per billion) decrease in ozone concentration increases labor productivity by 5.5 percent. Chang et al. (2014) find similar results for industrial workers: the reduction of an outdoor pollutant increases the labor productivity, measured as the average time of tasks. In both cases, the authors argue that pollution control policies can be seen as an investment in human capital.

In global terms, Kjellstrom et al. (2009) have forecasted that the climate change effects, measured in terms of increase in average temperature, may negatively affect labor productivity, an effect that may be heterogeneously distributed across regions. They argue that the lost labor productivity will be greater in Southeast Asia, Central America, and the Caribbean, given the more intense heat in those locales. From the industrial side, Berman and Bui (2001) use an estimation of the total factor productivity and find positive effects of environmental regulation on productivity at a set of refineries in Los Angeles (USA) from 1972-1992, despite the high cost of abatement technologies.

The causality channel through which the environment affects labor productivity occurs through observable and unobservable effects, such as effort, health, and cognitive abilities (Graff Zivin and Neidell, 2013). The most direct observable impact may be the improvement in occupational health in terms of internal firm effects, which includes reorganization of the production process (Delmas and Pekovic, 2013), and also external effects, such as reducing air pollution (Chang et al., 2014).

These effects are also latent in the long run; for instance, Currie et al. (2009) examine the effects of pollutants on school attendance and find that the increase in carbon monoxide $(C O)$ emissions, even when below federal air quality standards, significantly raises absences. Their results suggest that the substantial decline in $C O$ levels over the past two decades has yielded economically significant health benefits, which also have consequences for future generations.

It is important to keep in mind that the environmental dimension is included in this dual econ-

\footnotetext{
${ }^{5}$ The negative externalities on the environment should not be thought of exclusively as carbon dioxide $\mathrm{CO}_{2}$ emissions, but as a set of pollutants, or environmental degradation in general, that may lower labor productivity.
} 
omy model via the interaction between negative externalities from the $M$ sector, and the positive effects of environmental quality on labor productivity and savings. However, Lewis (1954, 1955 and 1958) was not explicitly concerned with the impact of economic growth on natural resources but rather the opposite. In addressing the issue of the scarcity of natural resources, Lewis (1955) referred to Malthus and Ricardo, his classical inspirations, which had a pessimistic view. In this sense, this green extension enriches the 60 -year-old Lewis model with a modern notion about environmental economics.

It is now possible to build on this intuitive discussion to flesh out the model in stages, starting with the baseline structure.

\section{The model}

The model starts by considering that the $M$ sector jointly produces two outputs: the $M$ good and a flow of pollution, $z$. Hence, the production of every unit of $M$ generates some level of externalities, but following Copeland and Taylor (2003), the amount of pollution released in the environment will differ from the amount generated if there is abatement. In the present instance, however, the fraction of $M$ output dedicated to abatement, $\phi$, is determined by an environmental authority, and it is not a choice variable of the firm. Increases in $\phi$ reduce the net flow of pollution, but at the cost of, say, primary inputs from $M$ production. Equivalently, it is possible to interpret the $M$ sector as producing a given level of gross output, and using a fraction $\phi$ to abatement. This leaves the $M$ sector with a net output to be sold in the goods market which is given by:

$$
M=(1-\phi) K^{\alpha}\left(\xi L_{M}\right)^{1-\alpha},
$$

in which $M, L_{M}$, and $K$ are output, employment, and capital stock in the $M$ sector, with $0<\alpha<1$, while $\xi$ is a labor productivity measure. ${ }^{6}$ The level of this productivity measure is given by $A \epsilon$, where $A$ represents the level of technology and $\epsilon$ denotes the level of environmental quality. Therefore, the growth rate of this productivity measure is given by the growth rate of the environmental quality, $\hat{\epsilon}$, plus an exogenous growth component, $\sigma$ :

$$
\hat{\xi}=(\sigma+\hat{\epsilon})
$$

In the Solow exogenous growth model a similar effect represents the state of technology only, which grows exogenously, and in the present instance, such exogenous growth is captured by $\sigma$. We are augmenting this interpretation to feature changes in labor productivity being also affected by changes in the environmental quality. In line with the empirical evidence, which finds a negative association of pollution and labor productivity, we suppose that the accumulation of environmental

\footnotetext{
${ }^{6}$ Note that in such circumstances, the abatement technology uses the same factor intensity as the Modern sector. Copeland and Taylor (2003) show that this is an easy way to capture the notion that abatement is costly, but avoids the complexity of modeling another sector, and/or another technology.
} 
quality creates conditions for an expansion of this productivity measure, $\xi$ (a property of the labor force). We are augmenting the standard prediction of EKC to capture the possibility of reverse causality between environmental quality and economic growth, which is one of the sources of pollution costs in the model. Thus, it is supposed that the levels of technology and environmental quality jointly determine labor productivity.

Another source of cost is measured by $\phi$, the fraction of the $M$ product that must be dedicated to pollution abatement, which is made endogenous to the level of environmental quality, and is defined according to the following rule:

$$
\phi=(1-\epsilon / E)
$$

where $E$ is a maximum attainable level of environmental quality, which is used by the government authority as a benchmark in the abatement rule. ${ }^{7}$ The level of $E$ is given exogenously by intrinsic characteristics of the environment. It is supposed that the environmental authority is risk averse, and committed to the biophysical limits of the Planet, taking into account the maximum attainable level of environmental quality. When the current level of environmental quality falls below $E$, the government requires that the $M$ sector uses a fraction of the $M$ output in the abatement activity. Given the specification in (3), the current level of environmental quality, $\epsilon$, cannot be higher than its maximum attainable level, while the abatement activity only ceases with $\epsilon=E$.

In the surplus labor phase, the actual amount of pollution released in the environment is given by the net flow of domestic negative externalities plus the pollution coming from developed countries, which ceases at the mature phase. The corresponding functions (in intensive units, $k \equiv K / \xi L$ ) in each development phase are defined as follows:

$$
\begin{gathered}
z_{U}=\left(\gamma_{1}-\gamma_{2} \phi\right) k^{\mu}-\gamma_{0}, \\
z_{M}=\left(\gamma_{1}-\gamma_{2} \phi\right) k^{\mu},
\end{gathered}
$$

in which $\gamma_{0}$ is an exogenous pollution parameter, $\gamma_{1}$ is a catch coefficient, which measures the negative impact of $k$ on the environment, and $\gamma_{2}$ is a productivity parameter that measures the $M$ sector's efforts at abatement, all these parameters being strictly positive. As the negative externalities are a joint production mechanism, $\mu$ is a scale effect, which is equal to 1 along the surplus labor phase, and to $\alpha$ in the mature one, in line with the effect of capital intensity in efficiency units in a general Lewis model (Ros, 2013). Hence, we follow a similar optimistic scenario for the EKC as modeled in Brock and Taylor (2010).

When the $M$ and $T$ sectors coexist they produce the same good. This single good, which is sold in a competitive goods market, and whose price is normalized to unity, is produced in the $T$ sector under constant returns to scale:

\footnotetext{
${ }^{7}$ Therefore, $\lim \phi_{\epsilon / E \rightarrow 0}=1$, and $\lim \phi_{\epsilon / E \rightarrow 1}=0$.
} 


$$
T=\xi L_{T}
$$

where $T$ and $L_{T}$ are the output and employment in the $T$ sector. It is supposed that the productivity of the labor force employed in the $T$ sector is also affected by the level of environmental quality. However, as it is solely the (capital-using) production in the $M$ sector which generates a flow of pollution, the pollution abatement rule in (3) does not apply to the $T$ sector. For the sake of simplicity and tractability, we further assume that the productivity measure represented by $\xi$ refers to the entire labor force, regardless of the sector where it is employed. Therefore, the specification in (2) applies to the effective labor in the $T$ sector as well, which means that we are implicitly assuming that the $T$ sector is also subject to the exogenous growth of labor productivity given by $\sigma$. Finally, we assume that there is no open unemployment, $L=L_{T}+L_{M}$, with the labor force growing at the exogenous rate $n>0$, in both development phases.

In the surplus labor phase, the marginal product of effective labor in the $T$ sector is constant, and thus the average product of effective labor, $T / \xi L_{T}$, remains constant as well. The $M$ sector hires labor from the $T$ sector by paying a constant wage premium, $f-1$, over the average product of effective labor in the $T$ sector, so that $w=f w_{T}$. Since $f$ is constant, the wage premium can be normalized to zero (so that $f=1$ ) without it making any significant qualitative difference to the analysis that follows. Therefore, it follows that $w=1$, and the labor force does not constrain capital accumulation for as long as the two sectors coexist.

When maturity is reached, labor supply becomes inelastic, and the present Lewis model behaves like the Solow (1956) model. In this phase, workers receive a wage equal to their marginal productivity. Thus, from the competitive labor and capital market equilibrium conditions, and profit-maximizing behavior on the part of the firms in the $M$ sector, it follows from (1) that:

$$
\begin{aligned}
& r=\alpha(1-\phi)^{1 / \alpha}\left[\frac{1-\alpha}{w}\right]^{\frac{1-\alpha}{\alpha}}, \\
& w=(1-\alpha)(1-\phi)\left[\frac{K}{\xi L_{M}}\right]^{\alpha} .
\end{aligned}
$$

Note that the profit rate in (7), $r$, depends on the real wage in both phases of development. From (7) first with $w=1$ and $L_{T}>0$, and then with $w$ being determined by (8), and $L_{T}=0$, respectively, the profit rate in each developing phase is given by:

$$
\begin{gathered}
r=\alpha(1-\phi)^{1 / \alpha}(1-\alpha)^{\frac{1-\alpha}{\alpha}} \\
r=\alpha(1-\phi) k^{\alpha-1}
\end{gathered}
$$

The existence of surplus labor counterbalances the operation of the decreasing marginal returns to capital, but the net result depends on (3). In the mature phase, the profit rate depends negatively on $k$. Capital accumulation in the $M$ sector raises labor demand, but the supply of labor is now inelastic, and the available labor force becomes a binding constraint.

From these structural equations, a comment as regards the notion of Sustainable Development 
(SD) discussed in the environmental literature (e.g. Neumayer (2010)) is in order. In the present instance, SD is the capacity to provide non-decreasing utility for future generations. The arguments of such implicit utility function include physical capital, and some level of environmental quality. It is supposed that natural and physical capital are substitutes and that all negative environmental impact may be reversible in the very long run. Therefore, this economy is modeled under the weak sustainability (WS) assumption.

In what follows, we describe the long run dynamics, when it is assumed that the economy is moving over time, with the state variables being the capital-labor ratio in efficiency units, $k$, and the level of environmental quality, $\epsilon$.

\subsection{The environmental and macroeconomic dynamics}

In the present instance, the environmental quality is modeled in a broad sense, abstracting its capacity of reproduction or intrinsic growth, and in this sense, we follow a similar approach as the one followed in the Green Solow model. First, it seems implausible not to take into account the environmental capacity of regeneration, but when we consider that natural environmental changes occur over a very long time horizon, generally $200-400$ years, it seems more plausible not to include these natural changes in a dynamic system that includes capital accumulation functions with shorter time horizons. ${ }^{8}$

Therefore, the level of environmental quality changes according to the negative influence of the flow of pollution in each development phase. Using (3), (4) and (5), such dynamics are given by:

$$
\begin{gathered}
\frac{d \epsilon}{d t}=\left[\left(\gamma_{2}(1-\epsilon / E)-\gamma_{1}\right) k-\gamma_{0}\right] \epsilon, \\
\frac{d \epsilon}{d t}=\left[\left(\gamma_{2}(1-\epsilon / E)-\gamma_{1}\right) k^{\alpha}\right] \epsilon .
\end{gathered}
$$

Recall that in the surplus labor (maturity) phase we have $\mu=1(\mu=\alpha)$. As regards $\gamma_{0}$, in the mature phase the economy stops receiving transfer of foreign pollution, and thus $\gamma_{0}=0$. Note also that we make the change in environmental quality to depend on the level of capital-labor ratio in efficiency units, and not solely on capital accumulation. In fact, empirical evidence presented in Marquetti and Pichardo (2013) suggest that labor intensive economies, and thus economies with lower capital-labor ratios, emit less $\mathrm{CO}_{2}$. Hence, it seems that it is not the amount of production, but the way that a particular economy produces, with more or less dirty capital stock per worker, that matters the most when it comes to model pollution dynamics.

The dynamics of the capital-labor ratio in efficiency units is given by:

$$
\frac{d k}{d t}=s r k-(n+\hat{\xi}) k
$$

\footnotetext{
${ }^{8}$ In general, when this intrinsic growth is take into account it is used a logistic function to model environmental dynamics. Theoretical and practical modeling discussions can be found in Arrow et al. (1995) and Brander and Taylor (1998), respectively. This analytical strategy is avoided here to maintain the model analytically tractable.
} 
in which firm-owner capitalists save a given fraction, $s$, of their profits in efficiency units of labor, given by $r k$. In addition, we assume, just for simplicity, that capital does not depreciate over time, whereas $n$ is the population growth rate, taken as exogenous. By definition, the proportionate rate of change of labor-augmenting technical change, $\hat{\xi}$, negatively affects $k$.

As with the level of environmental quality, the dynamics of the capital-labor ratio in efficiency units will vary according to each development phase. Therefore, first substituting (3), (4), and (9) into (13) under $T_{S}>0$, and then substituting (3), (4) and (10) into (13) under $L_{T}=0$, we have:

$$
\begin{gathered}
\frac{d k}{d t}=\Omega k(\epsilon / E)^{1 / \alpha}-(n+\sigma+\hat{\epsilon}) k, \\
\frac{d k}{d t}=s \alpha k^{\alpha} \epsilon / E-(n+\sigma+\hat{\epsilon}) k,
\end{gathered}
$$

where $\Omega=s \alpha(1-\alpha)^{(1-\alpha) / \alpha}$. Note that the level of environmental quality affects the capital-labor ratio in efficiency units both positively, by decreasing the fraction of $M$ output allocated to pollution abatement, and negatively through labor-augmenting technical change. The latter also defines the scale effect over the surplus labor phase, as discussed later on.

\subsubsection{Balanced growth and (in)stability}

The existence of these two development phases raises the possibility of multiple equilibria along the development path. Assuming that $\epsilon<E$, we can compute these equilibria given by $\dot{k}=$ $(d k / d t)=\dot{\epsilon}=(d \epsilon / d t)=0$. First, with the labor force being infinitely elastic at the subsistence wage in the underdevelopment phase, we have the following unique pair of economically relevant (that is, strictly positive) equilibrium values:

$$
\begin{gathered}
k_{U}^{*}=\frac{\Omega^{\alpha} \gamma_{0}}{\left(\gamma_{2}-\gamma_{1}\right) \Omega^{\alpha}-\gamma_{2}(n+\sigma)^{\alpha}}, \\
\epsilon_{U}^{*}=\left[\frac{n+\sigma}{\Omega}\right]^{\alpha} E .
\end{gathered}
$$

Even under weak sustainability assumptions the conditions for the existence of a positive real solution are very specific. ${ }^{9}$ As all parameters values in (16) and (17) are strictly positive, a strictly positive value for $k_{U}$ requires $\left(\gamma_{2}-\gamma_{1}\right) \Omega>\gamma_{2}(n+\sigma)$, which implies that abatement productivity must be higher than the catch coefficient. Note that the necessary condition given by $\left(\gamma_{2}>\gamma_{1}\right)$ is similar to the assumption of sustainable growth which appears in Brock and Taylor (2010), but in that case, it is the technological progress in abatement that must exceed growth in aggregate output in order for the flow of pollution to fall and the level of environmental quality to improve.

Regarding $k_{U}{ }^{*}$, the higher the parameters associated with negative externality effects, $\gamma_{0}$ and $\gamma_{1}$, the higher the ratio of capital to effective labor in equilibrium. The same is true for $n$ and

\footnotetext{
${ }^{9}$ In general, models with strong sustainability assumptions are not fully compatible with equilibrium models, since the biophysical limits of the planet are modeled according to the laws of thermodynamics.
} 
$\sigma$. Meanwhile, the greater is the abatement effort, the lower is the equilibrium value for $k$. As we have defined the change of $\epsilon$ as governed by anthrogenic reasons, the opposite is true for $\epsilon_{U}{ }^{*}$. Note also that the greater is the maximum attainable level for the environment, the greater is the steady-state value of environmental quality in the surplus labor phase, as further discussed later on.

The system of differential equation in (11) and (14) can be analyzed through a Taylor's expansion of the form $\dot{x}_{i}-x_{i}{ }^{*}=J_{U}\left(x_{i}-\dot{x}_{i}\right)$, in which $J_{U}$ is the corresponding Jacobian matrix, and $\dot{x} \equiv \partial x / \partial t$. The properties of the system can be qualitatively analyzed using local stability criteria. The Jacobian matrix, $J_{U}$, is given by:

$$
J_{U}=\left[\begin{array}{cc}
-\left[\frac{\gamma_{2} k^{*}}{E}\right] \epsilon^{*} & {\left[\gamma_{2}\left(1-\epsilon^{*} / E\right)-\gamma_{1}\right] \epsilon^{*}} \\
{\left[\frac{1 / \alpha \Omega \epsilon^{*}(1-\alpha) / \alpha}{E^{1 / \alpha}}+\frac{\gamma_{2} k^{*}}{E}\right] k^{*}} & -\left[\gamma_{2}\left(1-\epsilon^{*} / E\right)-\gamma_{1}\right] k^{*}
\end{array}\right] .
$$

Thus, using the corresponding equilibrium values it follows that:

$$
\begin{gathered}
J_{U_{11}} \equiv \frac{\partial \dot{\epsilon}}{\partial \epsilon}=-\frac{\gamma_{2} \gamma_{0}(n+\sigma)^{\alpha}}{\left(\gamma_{2}-\gamma_{1}\right) \Omega^{\alpha}-\gamma_{2}(n+\sigma)^{\alpha}}<0 \\
J_{U_{12}} \equiv \frac{\partial \dot{\epsilon}}{\partial k}=\frac{\left(\gamma_{2}-\gamma_{1}\right) \Omega^{\alpha}-\gamma_{2}(n+\sigma)^{\alpha}}{\Omega^{\alpha}}\left[\frac{n+\sigma}{\Omega}\right]^{\alpha} E>0 \\
J_{U_{21}} \equiv \frac{\partial \dot{k}}{\partial \epsilon}=\frac{\Omega^{\alpha}(n+\sigma)^{1-\alpha} \gamma_{0}}{\alpha E\left[\left(\gamma_{2}-\gamma_{1}\right) \Omega^{\alpha}-\gamma_{2}(n+\sigma)^{\alpha}\right]}+\frac{\gamma_{2}}{E}\left[\frac{\Omega^{\alpha} \gamma_{0}}{\left(\gamma_{2}-\gamma_{1}\right) \Omega^{\alpha}-\gamma_{2}(n+\sigma)^{\alpha}}\right]^{2}>0 \\
J_{U_{22}} \equiv \frac{\partial \dot{k}}{\partial k}=-\gamma_{0}<0 .
\end{gathered}
$$

Note that $J_{U_{11}}$ is negative, reflecting the fact that when the level of environmental quality increases the fraction of $M$ output used for abatement decreases, marginally decreasing as well the rate of change of $\epsilon$. Expectedly, this pattern also appears in the mature phase. Therefore, it is important to stress that this negative and self-correcting behavior arises in a context in which the environment is defined according to anthropogenic influences. Thus, each increase in the level of $\epsilon$ will marginally decrease its rate of change. If we had supposed that the intrinsic logistic growth rate of the environment also matters for the whole dynamics of the environment, this negative effect would be compatible with a situation in which the system is to the right of the maximum sustainable yield. ${ }^{10}$

The conditions for the existence and uniqueness of $k_{U}^{*}$ ensure that $J_{U_{12}}>0$, so that a rise in the capital-labor ratio in efficiency units raises the rate of change of $\epsilon$. The positive environmental effect on $k$, given by $J_{U_{21}}$, occurs through several channels. An increase in the level of environmental quality decreases the fraction of $M$ output dedicated to abatement, thus increasing profits and, therefore, savings. Note also that a rise in $\epsilon$ will speed up the rate of change of the capital-labor ratio in efficiency units, ceteris paribus, via indirect effects of the corresponding decrease in $\dot{\epsilon}$.

\footnotetext{
${ }^{10}$ The maximum sustainable yield is the largest average catch that can be captured from a stock of environmental quality under existing environment conditions.
} 
Finally, as the effect of $k$ on $\dot{\epsilon}$ is positive, the corresponding increase in the level of environmental quality lowers the capital-labor ratio in efficiency units required to yield $\dot{k}=0$.

The determinant of the Jacobian matrix in the underdevelopment phase, $\left|J_{U}\right|$, is given by:

$$
\left|J_{U}\right|=-\alpha^{-1}(n+\sigma) \Omega^{\alpha} \gamma_{0}<0
$$

which is unambiguously negative. Therefore, the equilibrium in the surplus labor phase is a saddlepoint, which is represented in Figure 1. The phase portrait is presented in panel (a), while a vector field simulation is presented in panel (b). The simulation parameters are plausible, but arbitrary, and the conditions for existence of a real positive solution for $k$ and $\epsilon$ are satisfied.

The axis are the respective levels for $\epsilon$ and $k$, with the two demarcation curves intersecting at the equilibrium point $U^{*}$ and dividing the system into four distinct regions. Recall that $J_{11}<0$, and thus, when the level of environmental quality is continuously increasing ( $\epsilon$-axis), the rate of change of $\epsilon$ undergoes a steady decrease, so that $\dot{\epsilon}$ is positive (negative) below (above) the $\dot{\epsilon}=0$ isocline. Meanwhile, when the capital-labor ratio in efficiency units is increasing ( $k$-axis), its rate of change is decreasing, with $\dot{k}$ being positive (negative) to the left (right) of $\dot{k}=0$. Both curves are positively related in the neighborhood of $U^{*}$, and thus, note that even facing an infinitely elastic labor supply, capital accumulation is environment-constrained in the underdevelopment phase. ${ }^{11}$

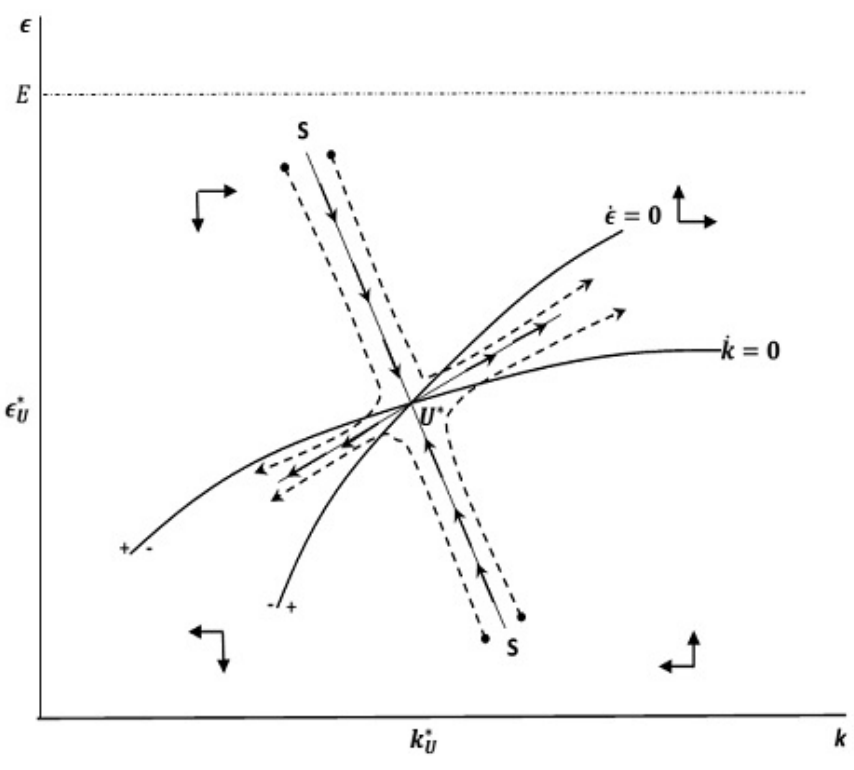

(a) Equilibrium in the surplus labor phase.

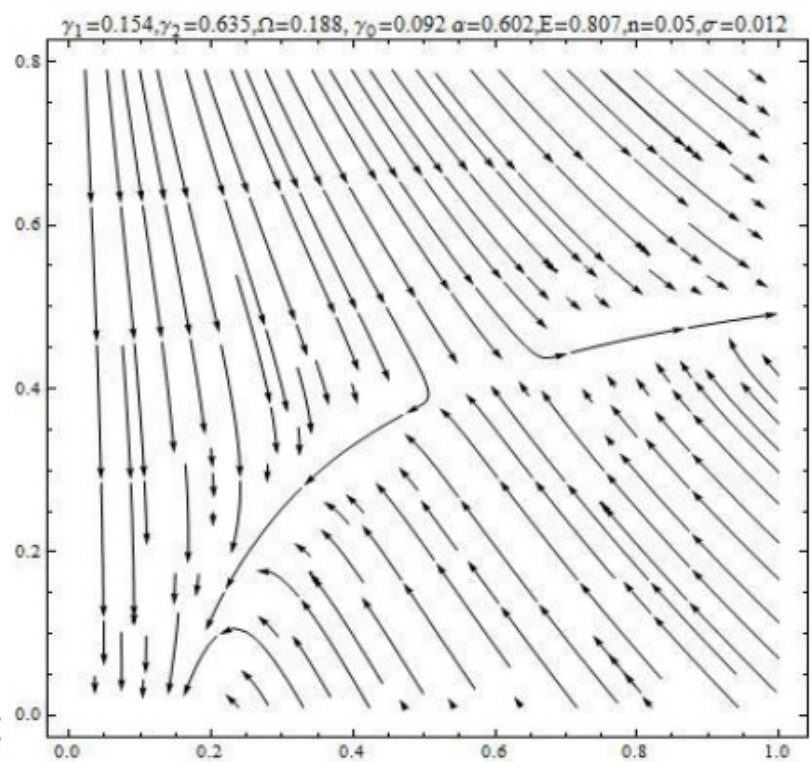

(b) Vector field simulation.

Figure 1: Saddle-point instability in the surplus labor phase.

Note also that the stable arm of the saddle-point, the separatrix $S S$, has a negative slope. All the area to the left of such stable arm constitutes what it is called here an ecological development

\footnotetext{
${ }^{11}$ These are plausible slopes of the curves; only the positive slope of both curves in the neighborhood of the unique equilibrium is important to the argument. It can be checked that, in the neighborhood of $U^{*}$, the $\dot{\epsilon}=0$ isocline, whose slope is given by $-J_{11} / J_{12}$, is steeper than the $\dot{k}=0$ isocline, whose slope is given by $-J_{21} / J_{22}$.
} 
trap, in which either one or both state variables experience a steady downward pressure. If the system starts to the left of $S S$ there are no endogenous forces capable of reverting such downward pressure. This trap is called ecological because it arises from a pollution abatement rule enforced by an environmental authority concerned with the biophysical limits of the Planet. The economic consequences of this trap are explored in the next section.

Note that a necessary condition for the existence and uniqueness of the ecological development trap is the presence of a pollution abatement mechanism that operates when the current level of environmental quality is below its maximum attainable level. As we are interested in exploring the macrodynamic effects of such an environmental policy, we can focus our attention on the case that $\epsilon<E$, though. In fact, recall that according to (3), when $\epsilon$ is equal to $E$, the fraction of the $M$ output allocated to abatement is null. As a result, it can be checked that the profit rate in the surplus labor phase (given in 9) becomes solely determined by the parameters of the production function. Meanwhile, it follows from (11) and (14) that there is no pair of economically relevant equilibrium values in the surplus labor phase when $\epsilon=E$, given that $\dot{\epsilon}$ is unambiguously negative. And, according to (12) and (15), the same applies to $\epsilon=E$ in the mature phase.

Assuming that the economy overcomes the underdevelopment stage, let us analyze the behavior of the laws of motion of the state variables in the mature phase, when the labor supply becomes inelastic. First, computing $\dot{k}=\dot{\epsilon}=0$, the unique economically relevant pair of equilibrium values is given by:

$$
\begin{gathered}
k_{D}{ }^{*}=\left[\frac{s \alpha\left(\gamma_{2}-\gamma_{1}\right)}{\gamma_{2}(n+\sigma)}\right]^{\frac{1}{1-\alpha}} \\
\epsilon_{D}^{*}=\left[\frac{\gamma_{2}-\gamma_{1}}{\gamma_{2}}\right] E
\end{gathered}
$$

Intuitively, the steady-state value of the level of environmental quality varies positively with the abatement effort and the maximum attainable level of environmental quality that is used as a benchmark by the government, but negatively with the catch coefficient, an immediate implication of (12). The same is true for the steady-state value of the capital-labor ratio in efficiency units. As in the underdevelopment equilibrium, the system is qualitatively analyzed using the criteria for local stability from the Jacobian matrix. Thus,

$$
J_{D}=\left[\begin{array}{cc}
-\left[\frac{\gamma_{2} k^{* \alpha}}{E}\right] \epsilon^{*} & {\left[\alpha\left(\gamma_{2}\left(1-\epsilon^{*} / E\right)-\gamma_{1}\right) k^{* \alpha-1}\right] \epsilon^{*}} \\
{\left[\frac{s \alpha k^{* \alpha-1}}{E}+\frac{\gamma_{2} k^{* \alpha}}{E}\right] k^{*}} & {\left[\frac{(\alpha-1) s \alpha k^{* \alpha-2} \epsilon^{*}}{E}-\alpha\left(\gamma_{2}\left(1-\epsilon^{*} / E\right)-\gamma_{1}\right) k^{* \alpha-1}\right] k^{*}}
\end{array}\right] .
$$

Substituting the corresponding equilibrium values it follows that:

$$
\begin{gathered}
J_{D_{11}} \equiv \frac{\partial \dot{\epsilon}}{\partial \epsilon}=-\left[\frac{s \alpha\left(\gamma_{2}-\gamma_{1}\right)}{\gamma_{2}(n+\sigma)}\right]^{\frac{\alpha}{1-\alpha}\left(\gamma_{2}-\gamma_{1}\right)}<0 \\
J_{D_{12}} \equiv \frac{\partial \dot{\epsilon}}{\partial k}=0
\end{gathered}
$$




$$
\begin{gathered}
J_{D_{21}} \equiv \frac{\partial \dot{k}}{\partial \epsilon}=\left[\left(\frac{s \alpha\left(\gamma_{2}-\gamma_{1}\right)}{\gamma_{2}(n+\sigma)}\right)^{\frac{\alpha}{1-\alpha}}+\frac{\gamma_{2}}{E}\left(\frac{s \alpha\left(\gamma_{2}-\gamma_{1}\right)}{\gamma_{2}(n+\sigma)}\right)^{\frac{\alpha+1}{1-\alpha}}\right]>0, \\
J_{D_{22}} \equiv \frac{\partial \dot{k}}{\partial k}=(\alpha-1)(n+\sigma)<0 .
\end{gathered}
$$

The effect of $\epsilon$ in $\dot{\epsilon}, J_{D_{11}}$, remains negative, but now the effect of the capital-labor ratio in efficiency units on the rate of change of the level of environmental quality in the neighborhood of the equilibrium, is null. This feature is similar to a result of the Green Solow model, according to which the environmental rate of change is independent of the level of $k$. However, here the existence of decreasing marginal returns to capital is not a sufficient condition for a lowering of the amount of negative externalities on the environment. Despite $J_{D_{21}}$ is capturing the effect of decreasing marginal returns to capital, its sign remains the same, but with a smaller marginal effect than in the underdevelopment phase. The same is true for $J_{D_{22}}$, which cannot be determined directly by $J_{D_{12}}$. Note that the effect of $k$ on its rate of change is now solely captured by the effect of $k$ on the investment function.

As it turns out, the determinant of such Jacobian is unambigously positive:

$$
\left|J_{D}\right|=\left(\gamma_{2}-\gamma_{1}\right)\left[\frac{s \alpha\left(\gamma_{2}-\gamma_{1}\right)}{\gamma_{2}(n+\sigma)}\right]^{\frac{\alpha}{1-\alpha}}(1-\alpha)(n+\sigma)>0
$$

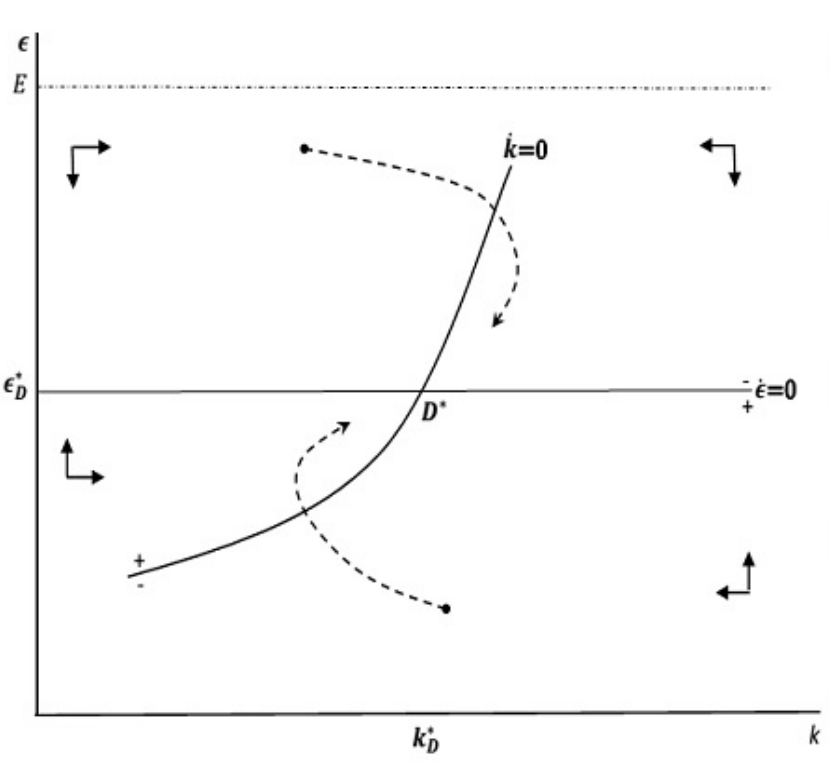

(a) Equilibrium in the mature phase.

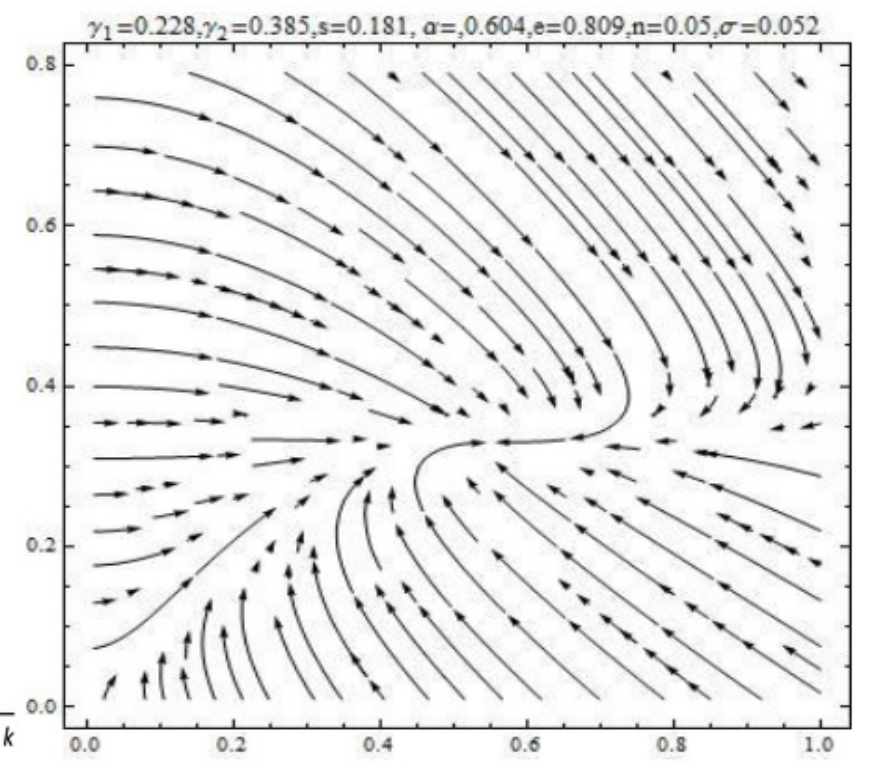

(b) Vector field simulation.

Figure 2: Stable equilibrium in the mature phase.

As the corresponding Trace, $\operatorname{Tr}\left(J_{D}\right)$, is negative, the equilibrium in the mature phase is locally stable. Figure 2 presents the phase portrait (panel (a)) and a vector field simulation (panel (b)) of the system in the neighborhood of the equilibrium. As $J_{D_{11}}<0$, when the level of environmental quality is increasing ( $\epsilon$-axis) its rate of change undergoes a steady decrease, so that $\dot{\epsilon}$ is positive (negative) below (above) the $\dot{\epsilon}=0$ isocline. The same remains true for $k$. When the capital-labor 
ratio in efficiency units is increasing, its rate of change experience a steady decrease, so that $\dot{k}$ is positive (negative) to left (right) of the $\dot{k}=0$ isocline.

While the $\dot{k}=0$ isocline remains positively sloped in the neighborhood of the equilibrium, the $\dot{\epsilon}=0$ isocline is now horizontal, given that $J_{D_{12}}=0$. Regarding the transition to such steady state, the mathematical properties of the system and the vector field simulation reveal that the convergence is in the form of a stable improper node. Hence, convergence to equilibrium occurs with monotonically increasing or decreasing levels of environmental quality and capital-labor ratio in efficiency units, a result qualitatively analyzed in the next section.

As the dynamics of the economy are influenced by a governmental policy, let us explore how the system reacts to an exogenous change in the maximum attainable level of environmental quality used as a benchmark by the environmental authority. Assuming that the exogenous change in $E$ is small enough, Figure 3 represents such comparative dynamics for the surplus labor and mature phases.

In the surplus labor phase, from (11) and (14), and the equilibrium values in (16) and (17), it follows that an initial positive shock in $E$ moves the $\dot{\epsilon}=0$ isocline leftward, thus positively affecting $\epsilon_{U}^{*}$. Meanwhile, as $k_{U}^{*}$ is not affected by $E$, the $\dot{k}=0$ isocline moves in such a way that $k$ returns to its original value. Note also that the $\dot{\epsilon}=0(\dot{k}=0)$ isocline becomes steeper (flatter) in the neighborhood of the new equilibrium. As the latter is a saddle-point, it is only by fluke that the system will converge to it. In addition, a possible rise in the size of the trap depends on the change in the slope of the separatrix $S S$.

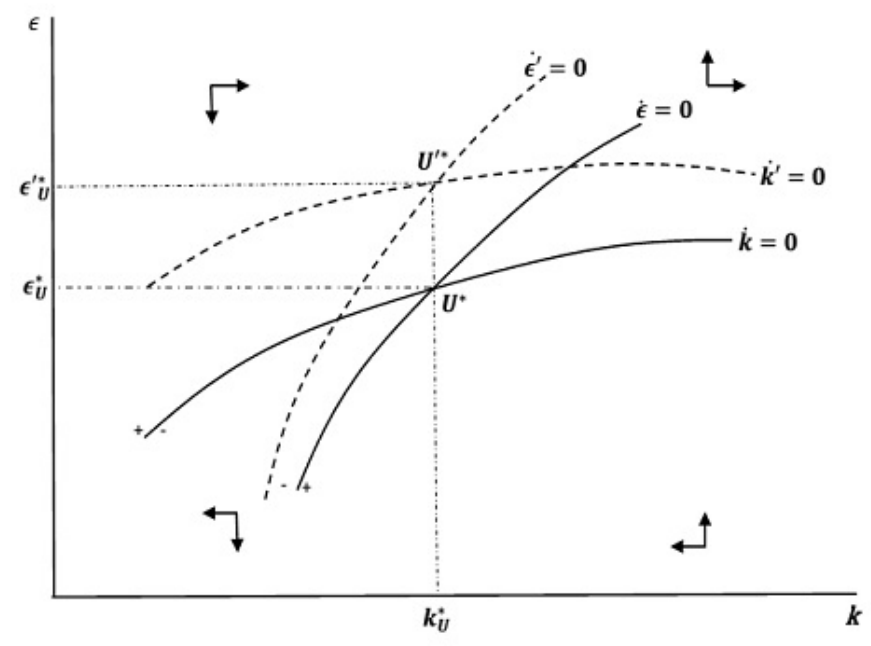

(a) Change in $E$ in the surplus labor phase.

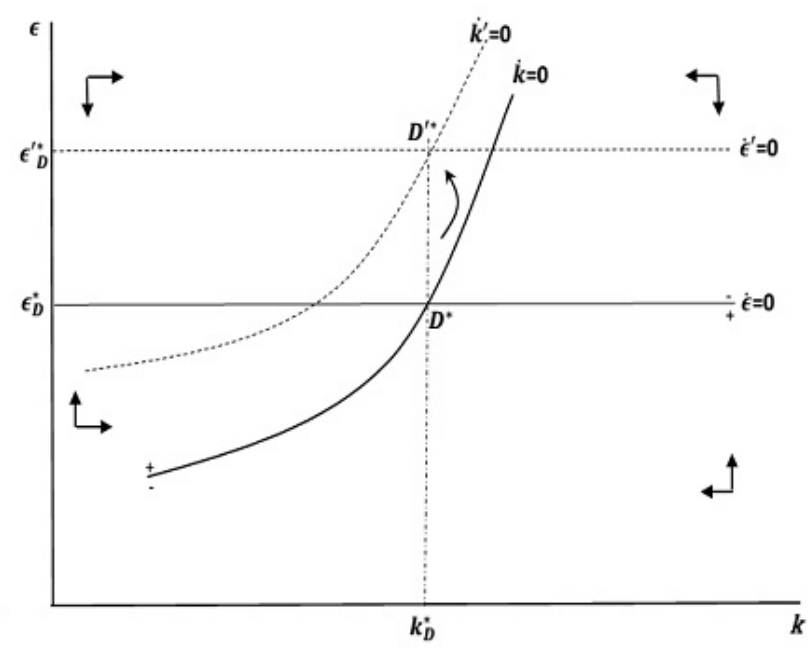

(b) Change in $E$ in the mature phase.

Figure 3: Comparative dynamics in each development phase.

In the mature phase, from (12) and (15), and the equilibrium values in (19) and (20), it follows that an exogenous increase in $E$ also moves the economy to a higher level of environmental quality, initially positively affecting $k$ as well. However, given (19), the equilibrium level of the capital-labor ratio in efficiency units is unaffected by $E$, so that the $\dot{k}=0$ isocline moves in such a way to restore $k_{D}^{*}$. In the process of adjustment, a higher environmental quality increases labor productivity, 
which in turn, lowers the required level of capital per effective worker in the economy. Note also that the $\dot{k}=0$ isocline becomes less steep in the neighborhood of $D^{\prime *}$. In both phases, the net effect of a higher value of $E$ is to increase the steady-state level of per capita income of the economy, as it increases the level of environmental quality and, therefore, labor productivity in the modern sector.

\subsubsection{Multiple equilibria analysis}

This section provides a further qualitative and illustrative representation of the dynamic system by combining the unique economically relevant equilibrium in each phase of development. Indeed, there is a set of parameters for which a joint representation of Figures 1 and 2 exists. A necessary condition for this is related to the slope of each isocline in the surplus labor phase, as pointed out earlier. Note also that with $L_{T}=0$, the $\dot{\epsilon}=0$ is horizontal, so that a possible multiple equilibria configuration can be illustratively represented as in Figure 4.

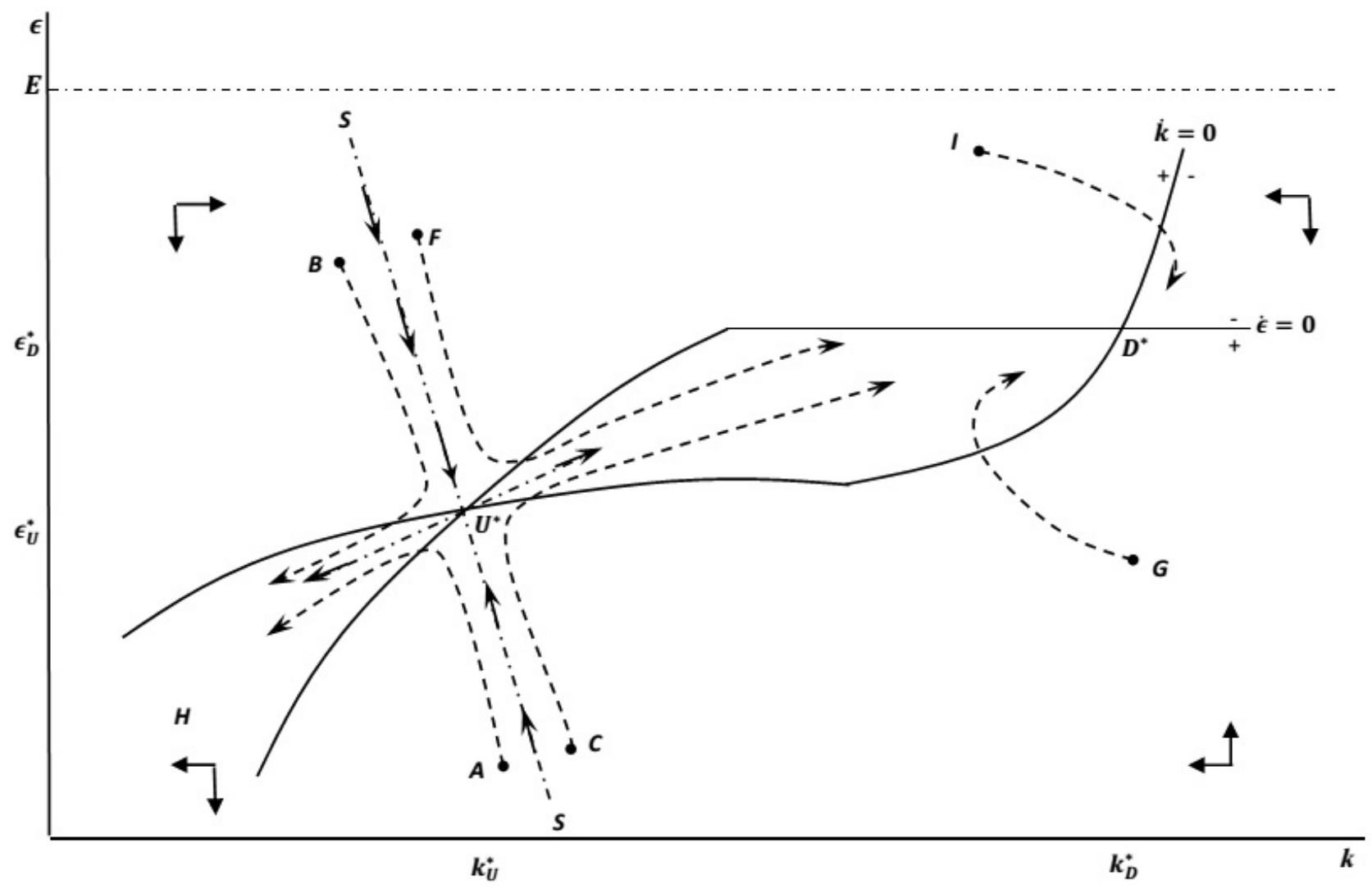

Figure 4: A possible configuration of multiple equilibria along the development path.

Consider, for example, that the system starts at point $A$, where the level of $\epsilon$ is relatively low, and the Modern sector must dedicate a relatively high fraction of its output to abatement. Since the level of environmental quality is relatively far from its maximum attainable level and the activity of cleaning up the environment is assumed to be effective, such positive effect overcomes the negative marginal impact of $\epsilon$ on $\dot{\epsilon}$, so that the level of environmental quality increases. Meanwhile, 
the capital-labor ratio in efficiency units is affected in two ways. First, as the fraction of output dedicated to abatement is relatively high at low levels of $\epsilon$, the net $M$ output (and, therefore profits and savings) is relatively lower. Second, at relatively low levels of $\epsilon$, the magnitude of the impact of the rise in the level of environmental quality on labor productivity is greater than the accompanying effect on savings, so that the capital-labor ratio in efficiency units falls along the trajectory started at $A$.

Conversely, if the economy starts at point $B$ the level of environmental quality is relatively high, and therefore, the fraction of the $M$ output dedicated to abatement is relatively low. Since the level of environmental quality is relatively high, the marginal effect of $\epsilon$ on $\dot{\epsilon}$ is greater than the positive effect of $k$ on $\epsilon$, so that the level of $\epsilon$ experiences a steady decrease. Meanwhile, the capital-labor ratio in efficiency units is affected in two ways. First, at point $B$ the level of pollution abatement does not compromise much the levels of profit and saving, so that capital accumulation is able to raise $k$. Second, the corresponding fall in $\epsilon$ requires a higher capital-labor ratio in efficiency units to yield $\dot{k}=0$. Note that at both points, $A$ and $B$, the development problem is the absence of a minimum level of environmental quality and/or capital stock per effective worker, which prevents the economy from being located somewhere to the right of the separatrix $S S$.

Consequently, the trajectories started at points $A$ and $B$ will eventually take the economy to a subset of the ecological development trap, the $H$ region. Once in this region the economy experiences a cumulative decline in environmental quality and capital intensity in efficiency units, which interact in a way of a vicious circle. As a result, the $H$ region illustrates the occurrence of a perverse Kaldor-Myrdal circular and cumulative causation mechanism of interaction between capital accumulation and environmental quality.

Note that even an economy with high levels of environmental quality which adopts a pollution abatement rule may fall in the Kaldor-Myrdal region of cumulative decline. This is in contrast with existing environmental macromodels, such as Brock and Taylor (2010) and Chimeli and Branden (2009). In these macromodels an economy which adopts an abatement policy will never experience a steady decline in the level of environmental quality. The result is a consequence of their sustainable growth assumptions and stability properties. In the present model, given the cumulative causation between capital accumulation and environmental quality, unfortunately this possibility arises quite naturally in the ecological development trap.

The size of the trap varies according to changes in $E_{U}$ and, as a consequence, in the separatrix $S S$. Therefore, the main effect of the pollution abatement rule assumed here is that a developing economy, if left to the free play of its structural forces, can be trapped in the underdevelopment phase. This theoretical result illustrates the claim of many developing countries regarding the possibility of a delay in the economic development process, given the backward effects caused by the unequal distribution of costs and benefits of pollution abatement and, more broadly, climate change. But if the economy starts to the right of the separatrix $S S$, for instance at points $C$ or $F$, it will converge towards maturity, even if it possibly slowly.

Once in the ecological development trap, the economy can be exogenously pushed from there to the right side of the separatrix $S S$ by means of a standard Big Push, in the sense of Rosenstein- 
Rodan (1943), whose real counterpart is an international compensation mechanism. This can be accomplished through an international mechanism of transfer of financial resources that exogenously increases the level of capital intensity in efficiency units, for the same level of environmental quality.

In the present model, the theoretical possibility of a Big Push is extended to an environmental dimension. If the economy is located to the left of the separatrix $S S$, the ecological development trap can also be overcome by means of what we call here an Environmental Big Push, $E B C$. While the case for a standard Big Push is well established in the economic development literature (see, e.g., Murphy et al. (1989), and Skott and Ros (1997)), this paper contributes to the environmental macroeconomics literature by providing a theoretical rationale for an Environmental Big Push. For instance, if the economy is in the $H$ region, an $E B C$ can push the economy from there to a point to the right of the separatrix $S S$, from which the convergence towards the mature equilibrium takes place, even if possibly slowly. The same possibility applies, of course, to points located out of the $H$ region, but still in the ecological development trap, such as points $A$ and $B$. Intuitively, as the level of environmental quality at point $A$ is lower than at point $B$, the capital-labor ratio in efficiency units is higher in the former.

Concretely, the Environmental Big Push can be interpreted, for instance, as an exogenous transfer of green technology developed in advanced economies to the abatement activity in developing economies, which will result in exogenous improvements in the level of environmental quality in the latter. In turn, the exogenous environmental recovery will lower the fraction of the $M$ output dedicated to abatement, which will raise the amount of savings available to finance investment. Moreover, the corresponding increase in the labor-augmenting technical change will require a lower capital-labor ratio in efficiency units to achieve similar productivity levels. Therefore, both effects are positive along the development path.

In the mature phase, unlike in Brock and Taylor (2010), our Green Lewis development model may not reproduce an $E K C$ pattern for the environmental dynamics. For instance, if the economy starts, by a fluke, in the mature phase, say at point $I$, with a relatively high level of environmental quality, the system experiences a monotonic fall in $\epsilon$ towards the steady state. Consider instead that the system starts at point $G$, where $k$ is relatively higher than $\epsilon$. The level of environmental quality experiences a monotonic increase towards $D^{*}$, while $k$ first fall and after some threshold it increases. This occurs because at $G$ the level of environmental quality is relatively far from its maximum attainable level, and the amount of $M$ output dedicated to abatement compromises the expansion of $k$. After the threshold the system enters a region of positive cumulative causation between environmental quality and capital-labor ratio in efficiency units that takes the economy to the steady state. ${ }^{12}$

\footnotetext{
${ }^{12}$ When the steady state at maturity, $D^{*}$, is reached, it follows from (1) with $L_{M}=L$ that the level of per capita income is given by $M / L=\alpha(1-\phi) k^{\alpha} A \epsilon$. Therefore, as both $k$ and $\epsilon$ are stationary in equilibrium, the steady-state growth rate of per capita income, as expected from the Solow (1956) nature of the mature development phase, occurs at the exogenous rate $\hat{A}=\sigma$.
} 


\section{Conclusions}

This paper extends a Lewis dual economy development model to explore the interaction between environmental quality and economic growth, according to a modern notion of sustainability. Although subject to the limitations of a stylized model, the main qualitative results derived in the paper contribute to shed light on ongoing heated political discussions about whether developing countries can simultaneously stimulate economic growth and reduce negative externalities on the environment. In fact, the most recent round of these discussions was just held at the 2015 Paris Climate Conference, where over 190 developed and developing countries agreed that they need to collectively chip in by curbing greenhouse gas emissions responsible for global warming, and doing so with specific targets and performance monitoring.

When compared to the Green Solow model set forth in Brock and Taylor (2010), our Green Lewis development model yields a less auspicious prediction about the interaction between economic growth and environmental quality in developing economies. This prediction is that a developing dual economy that faces an environmental constraint to economic growth-enhancing capital accumulation by dedicating a fraction of its output to pollution abatement may not achieve the mature, developed stage. The intuition for this prediction is that such pollution abatement requirement affects capital accumulation-enhancing profitability both negatively (by reducing marketable net output) and positively (by increasing labor productivity-enhancing environmental quality). As the relative strength of these two effects depend on the prevailing levels of environmental quality and capital intensity, there emerges an ecological development trap from which a developing dual economy, if left to the free play of its structural forces, never escapes. In fact, once in such ecological development trap, a developing dual economy is either already experiencing or will eventually come to experience a Kaldor-Myrdal circular and cumulative causation process of decline in capital intensity and environmental quality.

Fortunately, however, a developing dual economy can be released from such ecological development trap and eventually, even if slowly, overcome underdevelopment not only through a standard, capital-based Big Push, in the spirit of Rosenstein-Rodan, but also by means of what we call an Environmental Big Push. The latter could be based, for instance, on the adoption of international redress and compensation mechanisms in favor of developing economies. While the case for a standard Big Push is quite well established in the economic development literature, this paper is intended to contribute to the environmental macroeconomics literature by providing a sound theoretical rationale for an Environmental Big Push.

Finally, it should be emphasized that the emergence of an ecological development trap occurs in this paper in the context of a model developing economy which does not accumulate cleaner, less polluting capital. Therefore, a natural extension of this model (for which we invite the reader to stay tuned) is to incorporate the possibility of adoption of cleaner technologies. Admittedly, however, both the production and adoption of cleaner technologies are likely to be influenced, inter alia, by profitability considerations. More broadly, the Green Lewis development model set forth in this paper is expected to stimulate further research on other issues in ecological and environmental dynamics in developing economies. Given that global warming takes place in a global scale, it 
is especially appropriate to tackle these issues as they materialize in open developing economies, which may also require the use of stronger notions of sustainability.

\section{References}

Arrow, K. J., Bolin, B., Costanza, R., Dasgupta, P., Folke, C., Holling, C. S., Jansson, B.-O., Levin, S., Mler, K.-G., Perrings, C., and Pimentel, D. (1995). Economic growth, carrying capacity, and the environment. Science, 268(5210):520-521.

Berman, E. and Bui, L. T. (2001). Environmental regulation and productivity: evidence from oil refineries. The Review of Economics and Statistics, 83(3):498-510.

Brander, J. A. and Taylor, M. S. (1998). The simple economics of easter island: A ricardo-malthus model of renewable resource use. The American Economic Review, 88(1):pp. 119-138.

Brock, W. A. and Taylor, M. S. (2010). The green solow model. Journal of Economic Growth, 15(2):127-153.

Chang, T., Graff-Zivin, J. S., Gross, T., and Neidell, M. J. (2014). Particulate pollution and the productivity of pear packers. Working Paper 19944, National Bureau of Economic Research.

Chimeli, A. B. and Branden, J. B. (2009). A capital scarcity theory of the environmental kuznets curve. Environment and Development Economics, 14:541-564.

Copeland, B. R. (1991). International trade in waste products in the presence of illegal disposal. Journal of Environmental Economics and Management, 20(2):143 - 162.

Copeland, B. R. and Taylor, M. S. (1994). North-south trade and the environment. The Quarterly Journal of Economics, 109(3):755-787.

Copeland, B., R. and Taylor, M. S. (2003). Trade and the Environment: Theory and Evidence. Princeton University Press.

Currie, J., Hanushek, E. A., Kahn, E. M., Neidell, M., and Rivkin, S. G. (2009). Does pollution increase school absences? The Review of Economics and Statistics, 91(4):682-694.

Delmas, M. A. and Pekovic, S. (2013). Environmental standards and labor productivity: Understanding the mechanisms that sustain sustainability. Journal of Organizational Behavior, $34(2): 230-252$.

Graff Zivin, J. and Neidell, M. (2012). The impact of pollution on worker productivity. American Economic Review, 102(7):3652-73.

Graff Zivin, J. and Neidell, M. (2013). Environment, health, and human capital. Journal of Economic Literature, 51(3):689-730. 
Green, J. F., Sterner, T., and Wagner, G. (2014). A balance of bottom-up and top-down in linking climate policies. Nature Climate Change, 4(4):1064-1067.

IPCC (2014). Climate Change 2014: Synthesis Report, book section Contribution of Working Groups I, II and III to the Fifth Assessment Report of the Intergovernmental Panel on Climate Change, page 1141. IPCC, Geneva, Switzerland.

Jacob, M. and Marschinski, R. (2013). A balance of bottom-up and top-down in lininterpreting trade-related $\mathrm{CO}_{2}$ emission transfersking climate policies. Nature Climate Change, 3(3):19-23.

Kjellstrom, T., R. Kovats, S., Lloyd, S. J., Holt, T., and Tol, R. S. J. (2009). The direct impact of climate change on regional labor productivity. Archives of Environmental $\&$ Occupational Health, 64(4):217-227. PMID: 20007118.

Lewis, W. A. (1954). Economic development with unlimited supplies of labour. The Manchester School, 22(2):139-191.

Lewis, W. A. (1955). The Theory of Economic Growth. Manchester: George Allen Unwin Ltd.

Lewis, W. A. (1958). Unlimited labour: Further notes. The Manchester School, 26(1):1-32.

Marquetti, A. A. and Pichardo, G. M. (2013). Patrones de crecimiento y cambio tcnico en la produccin de un producto bueno y otro malo. Investigacin Econmica, 72(284):57-82.

Murphy, K. M., Shleifer, A., and Vishny, R. W. (1989). Industrialization and the big push. Journal of Political Economy, 97:1003-1026. Reprinted in Dilip Mookherjee and Debraj Ray, eds., Readings in Theory of Economic Development, Blackwell Publishing, 2001.

Nagashima, M., Dellink, R., van Ierland, E., and Weikard", H.-P. (2009). Stability of international climate coalitions a comparison of transfer schemes. Ecological Economics, 68(5):1476 - 1487.

Neumayer, E. (2010). Weak versus Strong Sustainability: Exploring the limits of two opposing paradigms. Edward Elgar.

Nurkse, R. (1952). Some international aspects of the problem of economic development. The American Economic Review, 42(2):pp. 571-583.

Razmi, A. (2015). North-south interactions in the presence of trade in environmental permits: a structuralist investigation. Cambridge Journal of Economics, 39:1-34.

Rosenstein-Rodan, P. N. (1943). Problems of industrialisation of eastern and south-eastern europe. The Economic Journal, 53(210/211):pp. 202-211.

Skott, P. and Ros, J. (1997). The "big push" in an open economy with nontradable inputs. Journal of Post Keynesian Economics, 20(1):149-162. 
Solow, R. M. (1956). A contribution to the theory of economic growth. The Quarterly Journal of Economics, 70(1):65-94.

Solow, R. M. (1974). Intergenerational equity and exhaustible resources. The Review of Economic Studies, 41:pp. 29-45.

Stokey, N. L. (1998). Are there limits to growth? International Economic Review, 39(1):pp. 1-31.

Verbruggen, A. (2009). Beyond kyoto, plan b: A climate policy master plan based on transparent metrics. Ecological Economics, 68(12):2930 - 2937. 